\title{
Scientific Project Presentation - Archive of Huambo's Library in Angola
}

\author{
Inês Morais
}

\begin{abstract}
This paper presents the scientific project of organizing, cataloging and analysis of historical file found in Huambo's Library in Angola. The aim is to portray a society and political processes in this region in the late nineteenth century until the second half of the twentieth century, under different aspects (interdisciplinary study, from economics, politics, law, sociology, culture, arts).
\end{abstract}

Index Terms-Historical archives, historical portrait, huambo, society.

\section{INTRODUCTION}

The scientific project belongs to the Centre for Applied Ethics of the Polytechnic Institute Rising Sun of Huambo in a partnership with Huambo's Department of Culture.

The aim is to conduct a historical study about the region (former Portuguese colony) since the late nineteenth century (1890) until the twentieth century, more specifically until 1975, year of the independence of Angola.

The working basis will be a collection of documents found in the Huambo's Library, 100 files containing documents from official sources and about different sujects. This source will allow the analysis of a Portuguese colony with all its specificities and its development over time.

The two main goals are mainly the organization and analysis of information from the archives found in the Library and the conservation and restoration of this historic heritage. This last goal has a crucial role in this project, given the precarious conditions of the documents, because of the effects of civil war that led to the looting and destruction of some material.

Another goal is to contribute to greater connection and understanding of today's society, serving the society itself as an important source of information.

Besides, that the idea is to bring students to work and contribute to this project that enables them to experience a scientific research in an application of theoretical concepts acquired in classes.

This research will enhance the understanding of this historical heritage contributing to their classification, valuation, distribution and promotion.

\section{Methodology}

The project's methodology will be based on three key stages and has different sources of information.

Manuscript received August 5, 2013; revised October 15, 2013.

Inês Isabel Morais is with the Instituto Superior Politécnico Sol Nascente, Huambo, Angola - Centre for Applied Ethics of the Polytechnic Institute Rising Sun of Huambo, Angola (e-mail: inesilisboa@hotmail.com).
The first stage focuses primarily on inventorying and cataloging the archive, using photos without flash to research and record the different documents and themes.

Besides that this will help us to understand which documents are damaged, that needs an urgent treatment, conservation and restoration.

Subsequently we will organize the documents in a chronological way, between 1890 and 1975. This stage has a major importance, because a coherent organization of the data is essential to understand the national history of both countries, Angola and Portugal.

The second stage is the collection and processing of information through the classification of sources. In this way, we intend to analyse interdisciplinary data, with the participation of teachers, researchers and students from different fields like history, politics, economics, law, culture, arts, among others.

Ultimately in a third stage, a final report will be built with all the information and findings during this scientific research.

Alongside the archive found in Huambo's Library, we will use a set of national sources, including Huambo's Seminar and Museum, as well as the Angola's Historic Archive, in Luanda. Alongside, we will do interviews to the employees from the Library or the regional government and to Huambo's citizens that went through some phases of this research.

International sources will be use as well, namely Torre do Tombo National Archive and National Library in Lisbon, Portugal, as well as the Archive Overseas History, historical archives of the Portuguese Ministry of Foreign Affairs (as it relates to the Office of Political Affairs from the former Ministry of Overseas before the independence of Angola in 1975), among other institutions and libraries.

In addition, we will check sources in the United States of America and United Kingdom, taking into account the reference in the archive of American and British citizens in Angola in the dates of this research.

Finally, we will do interviews to Portuguese citizens who lived in the region during that time, former Nova Lisboa, and can tell us about the society, institutions and the daily basis routine. The goal is to gather additional information to achieve a different and personal perspective, using real experiences.

\section{THE IMPORTANCE OF ARCHIVES}

According to Randall Jimerson (1977), "archives are places of knowledge, memory, nourishment, and power. Archives at once protect and preserve records; legitimize and 
sanctify certain documents while negating and destroying others; and provide access to selected sources while controlling the researchers and conditions under which they may examine the archival record" [1].

Documents, photographs, maps, drawings acquire special significance to understand a society. "They represent evidence, information, truth and social memory." (Jimerson, 1977) [1] They are an extension from a generation to another, a link to the essence of a society and a way to better understand it.

The Historic Environment Local Management (HELM) of the United Kingdom considers that the archives have a historical importance, which must be preserved for present and future generations. They are the cornerstone of any project, containing information of local landscapes as a true heritage of a nation [2].

In this way, the Huambo's archive is the key to this scientific project that enables the description of this society during the time it was a former portuguese colony.

Initial reports focus primarily in its historical route, including the physical transition from one place called Bailundo to Huambo, formerly called Nova Lisboa, where it was included in the Library.

\section{HuAmBo ANGOLA}

To understand this project we need to understand the framework.

Huambo is an Angola region with an area of 35.771,15 $\mathrm{Km} 2$ and has 2.301.524 people. It is organized under eleven municipalities: Huambo, Caála, Longonjo, Ukuma, Tchindjendje, Bailundo, Mungo, Londuimbali, Ekunha, Tchicala Tcholohanga and Katchiungo [3].

The capital of this region has the same name, Huambo and it is the second largest city of the country. It was established in 1912, by Norton de Matos and its first designation was Nova Lisboa (name remained until the time of Angola's independence) and achieved great prosperity during the colonial period [4].

During the civil war, 1975-2002, Huambo suffered greatly but at this moment efforts are being made to recover this region that was once one of the largest industrial parks and one of the greatest intellectual centers of Angola [5].

The Civil War destroyed buildings, namely the Library where the archive of this scientific project was located. Some documents were looted and many others destroyed by side effects, like fires and shots.

The material that remained intact was placed on Huambo's Seminar, a special request to the Bishop Francisco Viti. With the war over, the archive lost many documents during this all process and it was included in the current Huambo's Library, remaining there until today. This information was collected by interview method to the employees of the library and to the historian Festo Sapalo.

This library is called "Constantino Kamoli" and it is in the center of Huambo city. Follows the old library created in 1912 by Nova Lisboa city council and has about three thousands books, among novels, poetry and archives that tell the story of Angola and Portugal [5].

\section{First Data Collection - Stage I}

The archive, subject of this research, is in a corner in a bookcase with many shelves in the Huambo's Library. In this first stage and as we stated earlier, due to the archive inventory and catalog is possible to verify and record the themes, types of documents and subsequently the organization of the files (chronological and by areas).

It took three weeks to take more than 6.000 photos framed in 100 files. After doing these photos without flash was possible to make a general overview, verify the themes and the different subjects that allow a description of this region in a historical, social, political, economic, cultural way.

Like we said before it is a general overview, because this scientific project is still in the beginning and the first stage is still ongoing at this moment.

Next, we present some important notes:

- This first stage shows that the period of time that appears the most is between 1910 and 1930, because more than $50 \%$ of the archive belongs to the dates mentioned.

Only three files have documents before 1900, but we need to check every single file to prove this, because this date can appear in documents on other files.

We discovered that this archive is not perfectly organized and the consequence is the need to check all the archive to prove some facts.

- Each file has an inscription outside, most of them with a date and a place from Huambo region, for example: Bailundo, Balombo, Benguela, Bimbe, Chiumbo, Lepi. The name that appears the most is Bailundo in 55 files, one of the eleven municipalities of Huambo region.

This fact is due to the importance of Bailundo in that time, in many levels, especially political and strategic.

- The documents are from official institutions, like the regional government, the former court or the police station. The type of documents is mainly, official documents, telegrams, letters, charts, statistics and confidential information.

- Nova Lisboa City Council appears in approximately ten files, presenting documents about the last phase of the study time, 1960-1975.

Here we can see the political changes in the region and in some of them the effects of the April revolution in Lisbon, Portugal, in 1974.

The cultural services of Nova Lisboa Ciy Council were extremely active and many events took place in those times, exhibitions, books, articles in national or international newspapers about Huambo and a consistent work in the Library.

We are pretty sure that they were responsible for the organization and conservation of this archive before Huambo's independence.

- All of them present everyday situations as well as important historical facts that need to be study more carefully. Essentially, these documents help to undestand a society in a deep way and portray the relationship between two countries, Portugal and Angola.

- As we said earlier, one of the main goals of this scientific project is the restoration and conservation of this historic heritage. Due to its history and precarious conditions, the 
documents are damaged and may be lost forever if that work does not take place.

Many documents are burned and torn, for example. Older documents from the late nineteenth century (1890) or the beginning of the twentieth century have some texts that are unclear or we have more difficulty to see without the support of a magnifying glass.

As we said before besides the work with this archive, we have done interviews with employees from the "Constantino Kamoli" Library. They gave us the historical information and the path that this archive has made since early ages.

Besides them, we talked with the historian Festo Sapalo of the Regional Museum of the Upland. He gave us specific information, especially from the late nineteenth century and the beginning of the twentieth century. He talked with us about the riots in the end of nineteenth century.

Due to the presence of the Portuguese in the central highlands after the occupation, there were the riots in 1890 in Bié, under the King Ekuikui II. In 1896, after the death of Ekuikui II another rebellion has occurred in the reign of Nuna II. In 1902, came the decisive rebellion in Bailundo, in the time of King Kalandula, which resulted in the subjugation of the region by the Portuguese authorities. Bailundo falls in favor of Portugal and on August 8, 1912, General Norton de Matos created the city of Huambo and its first administrator was Artur Castro Soromenho.

\section{CONCLUSION}

The archive of Huambo's Library is the main tool for the portait of Angola society and specially this region and its evolution as a Portuguese colony until its independence in 1975. As a whole, this archive has important official documents that built a true and reliable image of a region that is boiling in several areas, as well this files show the construction and evolution of a society and its citizens and their social connection.

Besides, this project serves to rescue scientific documents completely decayed by time, because of the historical background (civil war) and precarious conditions of conservation that demand a urgent restoration of many of them and their integration into the national archive and historical heritage.

The beginning of this scientific project took place in 2013 by the Polytechnic Institut Rising Sun and will be developed in Angola and Portugal in an exchange of information for the correct validation of all documentation.

\section{REFERENCES}

[1] R. C. Jimerson, "Archives for all: The importance of archives in society," Archives, and the Public Interest, Midwestern Archivist, vol. 2, no. 2, pp. 20-21, 1977.

[2] Historic Environment Local Management. (1 July 2013). [Online]. Available: http://www.helm.org.uk/.

[3] Official Website of the government of Huambo. Available: http://web.archive.org/web/20070830073203/http://www.governodoh uambo.com/pag_27.htm.

[4] Infopedia. Thesaurus and Dictionary - Porto Editora. [Online]. Available: http://www.infopedia.pt/\$huambo.

[5] Angop. Agência Angola Press. Available http://www.portalangop.co.ao/angola/pt_pt/noticias/educacao/2013/6/ 27/Mais-100-leitores-visitam-diariamente-biblioteca-Constantino-Ka moli,5f381a84-d1d6-4c5b-ab2c-9dbe98a97daa.html.

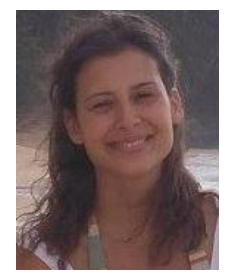

Inês Morais was born on 21 July 1982, she got he master degree in communication, culture and new technologies, ISCTE, Lisbon, Portugal. She has experience in public relations; She was a researcher in the University of Lisbon, Portugal and teacher and reseacrcher in the Polytechnic Institute Rising Sun of Huambo, Angola. Papers presented in the International Conference of Arts and Society, Berlin, 2011 and in the International Conference Destination Branding, Heritage \& Authenticity, in Santiago de Compostela, 2012. Publications in the International Journal of the Arts in Society, 2011 and in Rising Sun Publication, 2013. Her research interests are cultural marketing and arts; communication; cultural tourism 